\title{
A COMPARISON OF EXPERIMENTAL AND NUMERICAL BEHAVIOUR CHARACTERISTICS OF A SHIP ENTERING A LOCK USING BENCHMARK TEST DATA
}

(DOI No: 10.3940/rina.ijme.2016.a2.334)

M Vantorre and M Candries, Ghent University, Belgium, G Delefortrie, K Eloot and J Verwilligen, Flanders Hydraulics Research, Belgium, R Henn, Development Centre for Ship Technology and Transport Systems, Germany, T Vergote, Dredging International, Belgium, O Lindberg, FORCE Technology, Denmark, A de Loor, Deltares, The Netherlands, H-Z Wang and Z-J Zou, Shanghai Jiao Tong University, China

\section{SUMMARY}

This paper discusses several papers that were presented at the $3^{\text {rd }}$ International Conference on Ship Manoeuvring in Shallow and Confined Water, which had a non-exclusive focus on Ship Behaviour in Locks. For this conference, experimental model test data obtained at Flanders Hydraulics Research had been made public and researchers were encouraged to compare numerical with experimental results [1]. Data of benchmark tests carried out both with selfpropelled and captive models were used by researchers for comparison with various numerical tools. The objective of this paper is to give a selected overview of how accurately numerical tools are presently able to predict the hydrodynamic forces that occur on ships approaching locks. Based on this, the paper concludes that experiments and numerical tools complement each other.

\section{NOMENCLATURE}

AEP Expanded blade area divided by propeller area (-)

$B \quad$ Beam (m)

$C_{B} \quad$ Block coefficient (-)

$D_{P} \quad$ Propeller diameter $(\mathrm{m})$

$L_{O A} \quad$ Length over all (m)

$L_{P P} \quad$ Length between perpendiculars (m)

$T \quad$ Draught (m)

$P / D \quad$ Propeller pitch to diameter ratio (-)

$x \quad$ Longitudinal position (m)

$X \quad$ Longitudinal force ( $>0$ forward) (N)

$y \quad$ Lateral position (m)

$Y \quad$ Lateral force ( $>0$ to starboard) (N)

$z_{A P} \quad$ Sinkage at the aft perpendicular (sinkage $\left.>0\right)$ (m)

$z_{F P} \quad$ Sinkage at the forward perpendicular (sinkage $>$ 0) $(\mathrm{m})$

$Z \quad$ Yaw moment ( $>0$ bow to starboard) $(\mathrm{N} \mathrm{m})$

\section{INTRODUCTION}

Passing through a lock is a very specific ship manoeuvre where the ship moves at low speed and where the confined environment has a large effect on the hydrodynamic forces that occur. These involve more than just shallow water and bank effects. A series of additional effects such as density currents and the permeability of approach structures also have to be considered. Ultimately, complex ship hydrodynamics are involved, which are not yet fully understood. Vantorre and Richter [2] give an overview of these effects when a ship is approaching a lock and point out that most of these effects have a non-stationary nature, which is very challenging to put into mathematical models that drive manoeuvring simulators.

A clearer insight into the hydrodynamic behaviour of a ship entering or leaving a lock can be obtained by studying the flow field around the ship in detail, which can be achieved using numerical tools. However, these tools are complex and a reference is needed to interpret the physical correctness of the calculated results. To this end, experimental data are required either from tests carried out at model scale or from full-scale measurements.

For the $3^{\text {rd }}$ International Conference on Ship Manoeuvring in Shallow and Confined Water, which had a non-exclusive focus on Ship Behaviour in Locks, benchmark model test data obtained at Flanders Hydraulics Research had been made public and researchers were encouraged to submit papers that compared the results of numerical calculations with the benchmark test data of both self-propelled and captive models entering or leaving a lock.

This paper gives an overview of these comparisons and indicates how experimental data and numerical tools complement each other. Section 2 of the paper deals with tests with self-propelled models and Section 3 describes tests with captive models. Finally, some conclusions are given in Section 4 of the paper.

\section{TESTS WITH SELF-PROPELLED MODELS}

\subsection{EXPERIMENTAL DATA}

In 2007-2008, model tests were executed to investigate the behaviour of vessels transiting the future Panama Canal Third Set of Locks, presently under construction. Each of the six lock chambers will have a maximum length of $488 \mathrm{~m}$ between the lock gates. The width of each chamber will be $55.0 \mathrm{~m}$. The design ship is a socalled Post-Panamax 12000 TEU container carrier, with particulars given in Table 1 and body plan shown in Figure 1. The Consorcio Pos Panamax (CPP) 
commissioned model tests to determine design and operational criteria, such as the need and the configuration of lock approach walls and required tug assistance. For a detailed description of the test program and the main results, reference is made to [3] and [4]. A $1 / 80$ scale model of a lock and an approach channel was built according to the preliminary design of the Panama Canal Third Set of Locks, at Flanders Hydraulics Research, as shown in Figure 2.

Table 1: Ship characteristics

\begin{tabular}{|l|l|l|l|}
\hline PARTICULARS & & $\begin{array}{l}12000 \\
\text { TEU ship }\end{array}$ & $\begin{array}{l}\text { Scale } \\
\text { model } \\
1 / 80\end{array}$ \\
\hline SHIP & L $_{\mathrm{OA}}(\mathrm{m})$ & 365 & 4.563 \\
& $\mathrm{~L}_{\mathrm{PP}}(\mathrm{m})$ & 348 & 4.350 \\
& $\mathrm{~B}(\mathrm{~m})$ & 49 & 0.613 \\
& $\mathrm{~T}(\mathrm{~m})$ & 15.2 & 0.190 \\
& $\mathrm{C}_{\mathrm{B}}(-)$ & 0.65 & 0.65 \\
\hline PROPELLER & \#blades & 6 & 6 \\
& $\mathrm{D}_{\mathrm{P}}(\mathrm{m})$ & 9.40 & 0.118 \\
& P/D (-) & 1.07 & 1.07 \\
& AEP (-) & 1.03 & 1.03 \\
\hline RUDDER & Area $\left(\mathrm{m}^{2}\right)$ & 92 & 0.0144 \\
\hline
\end{tabular}

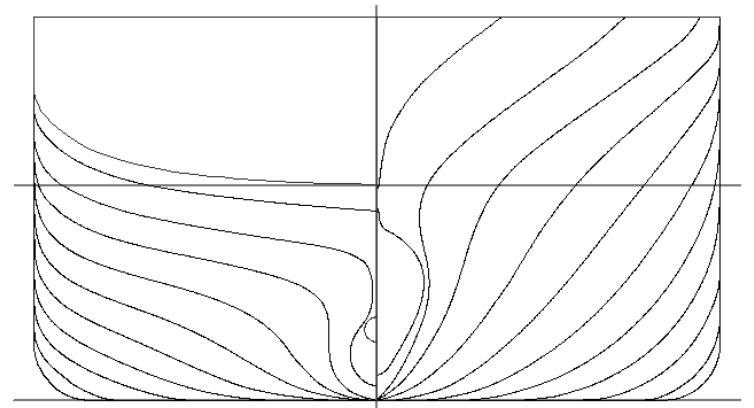

Figure 1: Design vessel for new Panama locks (12000 TEU container carrier): body plan.

The lateral forces in each connection point are measured by dynamometers, while the ship is free to move in vertical direction (heave, pitch and roll). The ship's velocity is controlled by changing the ship's propeller rate (rpm), or by tug assistance. This tug assistance is simulated by small model scale airplane propellers exerting longitudinal forces and mounted on the ship model.

The different test scenarios depended on a number of parameters, including the configuration of the approach wall; the overall water depth in the approach channel; the depth of the lock chamber with respect to the approach channel; the lateral position of the ship model with respect to the lock axis (eccentricity); density effects (i.e. exchange currents generated by a difference in density between fresh water in the lock chamber and salt water in the approach channel during spilling operations and during the opening of the lock gate) and ship controls. Table 2 gives an overview of the main characteristics of these parameters for the benchmark tests that were carried out with self-propelled models. Further details are given by Vantorre et al. [1].

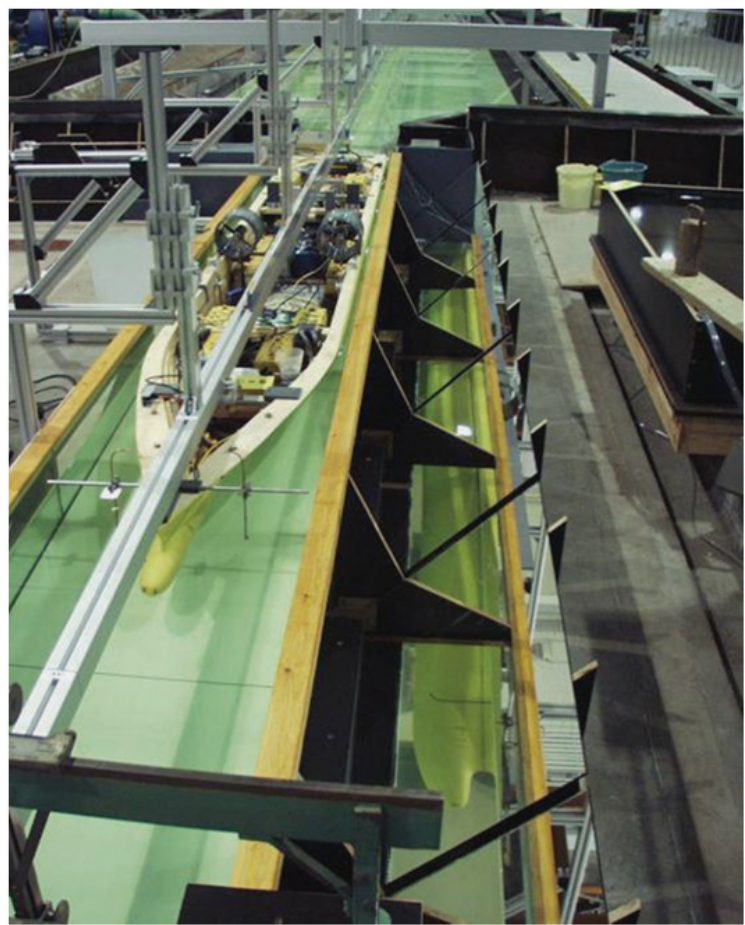

Figure 2: General view of the set-up for experiments with self-propelled models.

Table 2: Overview of benchmark tests with selfpropelled models (model scale).

\begin{tabular}{|c|c|c|c|c|c|c|}
\hline & 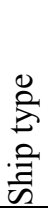 & 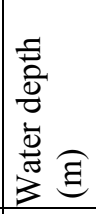 & 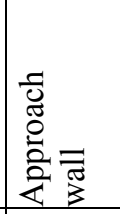 & 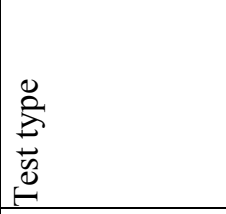 & 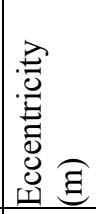 & 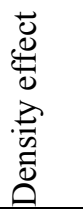 \\
\hline A & & 0.228 & Closed & Ocean $\rightarrow$ Lock & 0.000 & No \\
\hline $\mathrm{B}$ & & 0.209 & Closed & Ocean $\rightarrow$ Lock & 0.000 & No \\
\hline $\mathrm{C}$ & D & 0.228 & None & Lock $\rightarrow$ Ocean & 0.019 & No \\
\hline $\mathrm{D}$ & F & 0.228 & Closed & Lock $\rightarrow$ Ocean & 0.019 & No \\
\hline $\mathrm{E}$ & 융 & 0.228 & Closed & Lock $\rightarrow$ Lake & 0.019 & No \\
\hline $\mathrm{F}$ & ป & 0.228 & Closed & Ocean $\rightarrow$ Lock & 0.000 & Static \\
\hline
\end{tabular}

\subsection{USE OF BENCHMARK TEST A TO EVALUATE A FAST NUMERICAL SOLVING METHOD BY HENN}

Henn used benchmark test $A$ to evaluate a numerical method that is fast enough to be implemented in ship manoeuvring simulators [5]. The numerical method assumes an incompressible and inviscid fluid and the flow field can be described by the Euler equations. Assuming the waves to be long and the wave height to be small in relation to the water depth and following Boussinesq's approach, the Euler equations can be integrated vertically, taking the exact boundary conditions at the arbitrary bottom and free surface into 
account. Consequently, the three-dimensional flow field can be described by two velocity components in a horizontal plane and the local wave elevation (i.e. water depth). The special geometry of the narrow lock basin and the connected canal leads to a flow that is dominated in longitudinal direction. Still regarding the boundary conditions at the bottom, the side walls and the free surface, the field equations can be integrated in transverse direction to obtain a system of equations that describes the flow by a longitudinal velocity component and the wave elevation. Even though the water is assumed to be inviscid, frictional effects at the bottom and side walls are not neglected and a viscous component is applied at the bottom and the side walls. This component becomes more important the more confined the water is. The lateral integration assumes symmetry to the ship's midship plane. The equations neglect the effects of rudder(s) and propeller(s) on the flow, but the propeller thrust is included.

Since both lock manoeuvres and the numerical method are unsteady, it is important to apply appropriate initial conditions. The initial condition, including its derivatives, must be a solution of the governing equation system itself. The trivial solution can be used as initial condition: the simulation starts with calm water and a stopped ship. The ship is then accelerated to the final speed. This is exactly the manoeuvre the ship performs when leaving the lock. On lock entry, the acceleration phase can be simulated in an infinite long canal, so that at sub-critical speeds - the flow field converges to a stationary state. This flow field can be used as an initial condition for simulation of the actual manoeuvre starting near the lock. In this way, the simulation of a ship entering different locks with the same canal can be started with the same pre-calculated initial condition [5].

The ship motion is then described by Newton's law of motion and the sum of all longitudinal forces acting on the hull leads to the longitudinal acceleration. The wave resistance is calculated by integrating the pressure on the hull and the frictional resistance is calculated according to the ITTC' 57 correlation line with a correction for the local velocities on the hull.

The field equations are discretized in space and time using the symmetric Crank-Nicolson finite difference scheme. The resulting sparse matrix is solved by a standard SOR (successive over-relaxation) or GMRES (generalized minimal residual) method. The simulation starts with reading or calculating the initial condition. In a loop for each time step the linear system of equations is built and solved, the forces and accelerations are calculated and the ship is moved according to the actual velocities. The simulation ends when the given number of time steps has been simulated, the ship reaches the end of the calculation domain or the ship touches the ground.

Henn used the numerical method to compare the results with benchmark test $\mathrm{A}$, which was carried out with an under keel clearance of $20 \%$ of the ship's draft. In the experiments, the ship model was accelerated by means of its own propeller until a speed of 4 knots (full scale) was reached. At that time the propeller rpm was set to zero. One ship length before the ship's bow reached the approach wall, the propeller rate was set to dead slow while the ship's speed was maintained by the "tugs" to a value of 2 knots full scale until the ship was completely within the narrow section. Finally the model was stopped with all the power of the ship control available (ship propeller and "tugs").

Figure 3 compares the time histories of the measured and calculated ship speed and position. It can be seen that there is a relatively good agreement between the measurements and the simulation. Considerable oscillations in the simulated speed are present when the ship is entering the lock basin. The oscillations of the speed coincide with oscillations in heave and pitch motions. While the heave force and pitch moment are regarded in the calculation, the hydrodynamic damping of heave and pitch had been neglected. Due to the heave and pitch motions the ship radiates waves, that are reflected at the rear gate and lead to an overestimation of the speed (compared to the measurement) between $15 \mathrm{~s}$ and $30 \mathrm{~s}$ and to an underestimated speed between $60 \mathrm{~s}$ and $75 \mathrm{~s}$.

Figure 4 compares the time histories of the measured and calculated tug forces. They are difficult to compare precisely as these unsteady quantities should match in space and time.

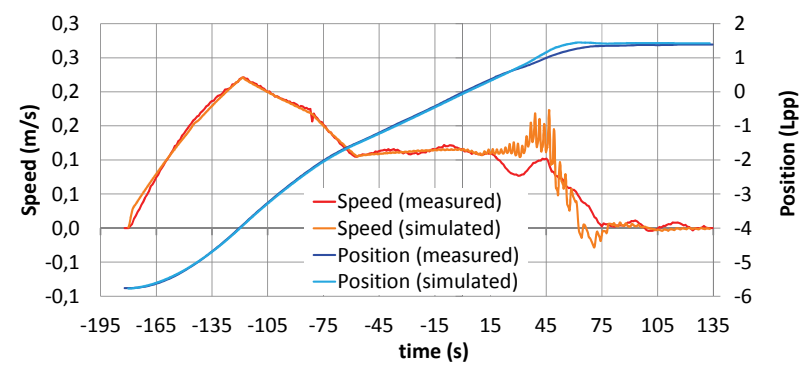

Figure 3: Time histories of the measured and the calculated ship speed and position for benchmark test A. The time axis has been shifted, so that $t=0$ where $x=0$.

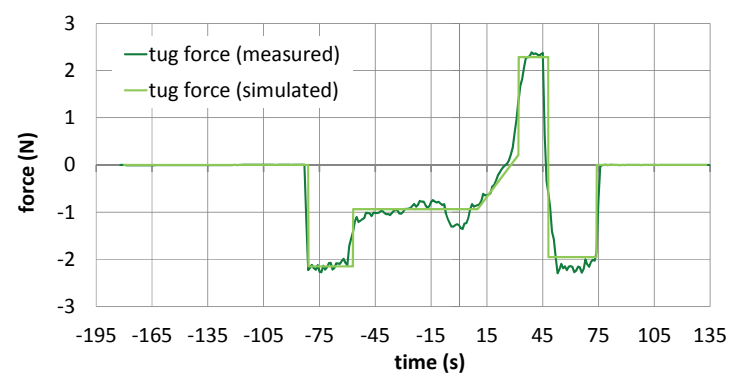

Figure 4: Time histories of the measured and simulated tug forces for benchmark test A.

Henn concludes that the numerical method is accurate enough to be used as a simulation tool for lock 
manoeuvres and is fast enough for real-time simulations, but lateral forces and yaw moments have not yet been regarded. There are plans to implement the numerical method into ship handling simulators to improve the accuracy while simulating lock manoeuvres. At the moment the simulator detects a ship approaching a lock, the simulator would switch from the standard parameter force model to the live CFD simulation [5].

\subsection{USE OF BENCHMARK TEST A TO VALIDATE AN IMPROVED SIX-WAVES MODEL BY VERGOTE ET AL}

Vergote et al. used benchmark test A to validate an improved six-waves-model describing the wave-system in a lock [6]. The six-waves model was originally proposed by Vrijburcht [7] and is used to calculate the translation waves generated by the lock entry of a pushtow. A one-dimensional approach is used, longitudinal water movements are considered and currents in vertical and cross-directions are neglected. The most important assumptions of the original six-waves-model are: the ship's speed is constant (1), the lock is closed at the end (2), no wave reflections are considered in the canal (3), the ship has a rectangular cross section (4) and the transfer from canal to lock is abrupt (5). The solution of the six-waves-model consists of two steps. First a system of equations of Bernoulli and continuity equations is solved, rendering water level and flow parameters. Then the wave height over a period is calculated for six waves: two initially generated waves, travelling respectively towards the end of the lock and towards the stern of the ship, and four reflected or transmitted waves.

Vergote et al. [6] improved this model by expanding its scope and by essentially changing the way the initial wave is generated. The assumption of a constant speed is changed by the introduction of a variable calculated speed and hence the initial wave at the bow will also change with every time-step. This has a significant influence due to the important deceleration during the entrance. A second improvement consists of the introduction of a realistic bow shape. The bow wave is then calculated as the accumulation of waves generated at every time-step due to the increasing width and crosssectional area of the ship at the lock entrance. A third improvement is the introduction of a realistic lock entrance with a gradually narrowing, rather than abrupt, transition between the canal and the lock section. As a result, translation waves will be generated earlier and the course of the wave height is smoother.

The original six-waves model was constructed for the entry of a push-tow. The adjustments to the six-waves model increased the potential scope of the model by introducing an adjustable shape of the bow. It can be expected that the model would give the best results for vessels with a relatively full form and high block coefficient. The performance of the model was tested for bulk carriers. Results from the model were compared to measurements of scale model tests carried out at Flanders Hydraulics Research for the West Lock of Terneuzen and of a full scale test in Dunkirk [6]. The results were generally favourable, with a good prediction of the generated translation waves and ship speed.

In order to assess the effectiveness of the improvements for slender ships, calculations carried out with the model for a container ship were compared with the results for benchmark test A. In Figure 5, the water level elevation is shown calculated both by the original method and the improved model.

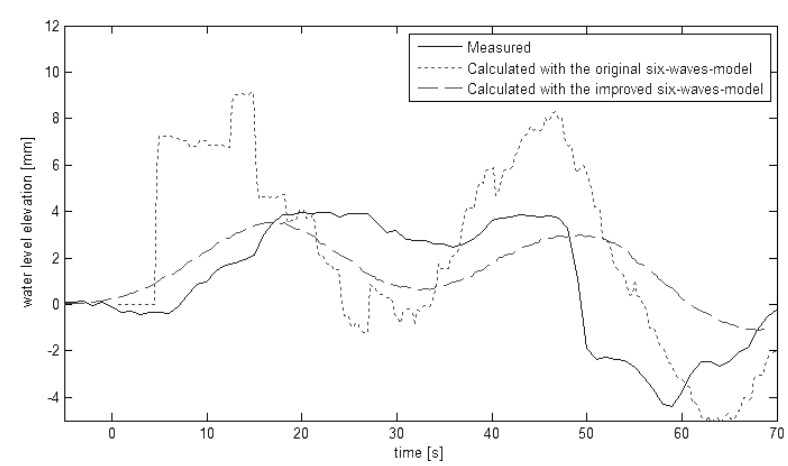

Figure 5: Water level elevation at the end of the lock, measured and calculated with the original and improved six-waves-model (benchmark test A: 20\% UKC)

It can be seen that during the first phase of the entry the improved model agrees much better with the experimental data than the original six-waves model. However, at around 50 seconds, the speed of the ship falls rapidly, resulting in a steep fall of the water level, which is not indicated well by the improved model.

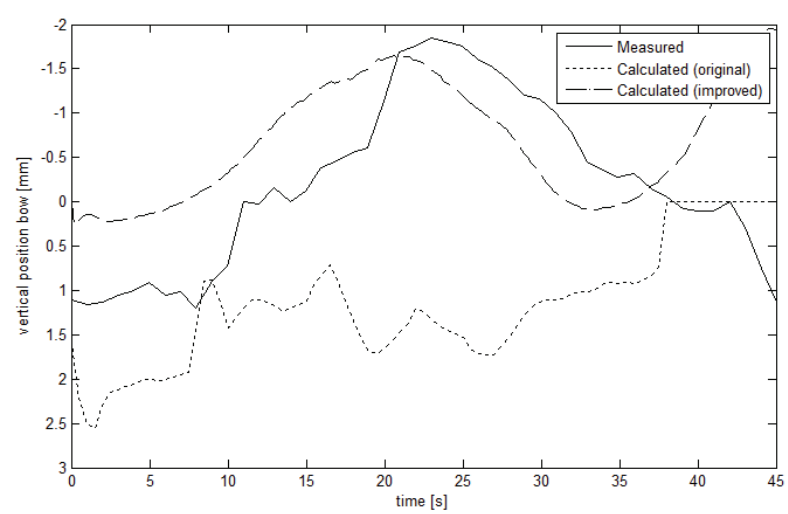

Figure 6: Vertical movement of the ship's bow, measured and calculated with the original and improved six-wavesmodel (benchmark test A). Negative values indicate that the bow moves upward, sinkage is positive.

Figure 6 shows the sinkage of the bow, where the calculations are greatly improved compared to the results of the original model. A bow-down trim is predicted by the original model, contrary to the predictions of both the improved model and experimental observations with the container carrier. The tendency of the sinkage of the bow as calculated with the improved model is relatively 
accurate, the bow of the ship first sinks in the water, and is pushed up once the reflected translation wave reaches the ship. However, the magnitude of the sinkage is quite sensitive to an experimental factor of Vrijburcht's system, and to the ship's speed [6].

The improved model is a typical engineering solution based on both a theoretical approach and pragmatic compensations for the necessary assumptions. The improved model only accounts for the one-dimensional hydrodynamic effects of the lock entrance and as a result wind effects, lateral forces, movements due to previous manoeuvres, etc. are not taken into account. In a ship simulator, all these effects should be accounted for and further improvement to the model is required to make the model appropriate for slender ships.

Due to the transparency of the six-waves-model and the effectiveness of the improvements, some experimental observations were also highlighted. For instance, the effect of the shape of the bow has a very important influence on the magnitude of the translation waves. Another less anticipated observation was the effect of the shape of the approach channel on the translation waves and the vertical movements of the ship. If the crosssection of the channel narrows gradually over a certain length towards the lock, then the translation wave is also generated more gradually by the lock entrance. The model is generally less reliable for slender vessels like container vessels as compared to bulk carriers, indicating that other effects come into play with slender hull shapes, which are not captured by the one-dimensional system of Bernoulli and continuity equations of the improved sixwaves-model.

\section{$2.4 \quad$ USE OF BENCHMARK TEST B TO ASSESS THE RANGE OF A REAL-TIME SIMULATION TOOL BY LINDBERG ET AL}

Lindberg et al. [8] used benchmark test B to evaluate whether a numerical model for real-time ship-wave calculation and ship-structure and ship-ship interaction in a full mission marine simulator could be applied for the case when a ship is entering a lock. The numerical model is based on potential flow theory that uses a linear or non-linear free surface boundary condition and higherorder accurate numerical approximations. The body boundary condition on the ship hull is approximated by a static and dynamic moving pressure distribution. The advantage of the pressure distribution method is that it is simple, easy to implement and computationally efficient. Multiple many-core graphical processing units (GPUs) are used for parallel execution and the model is implemented using a combination of $\mathrm{C} / \mathrm{C}++$, CUDA (Compute Unified Device Architecture) and MPI (Message Passing Interface).

The lock entrance of a 12000 TEU Container Carrier was calculated corresponding to benchmark test B. Benchmark test $\mathrm{B}$ follows a similar scenario as test $\mathrm{A}$, but is carried out at an under keel clearance of only $10 \%$. Moreover, the propeller is only used during the acceleration phase, while during the passage of the approach wall and the entrance of the lock the ship's speed was controlled by tugs only.

In the numerical model, the container carrier hull has been modified such that the depth is a single value function to the horizontal coordinates. The pressure distribution method is used for both the representation of the ship and the lock walls: the pressure pushes the surface to the bottom of the lock on the land side of the lock walls. This introduces large gradients in both the surface elevation and the surface potential at the walls.

Examples of the free surface elevation and free surface potential are given at two instances, with the container carrier in the entrance $\left(x / L_{p p}=4.5\right.$, Figure 7 and Figure $8)$ and along the approach wall $\left(x / L_{p p}=0.6\right.$, Figure 9 and Figure 10). The free surface elevation is reasonable when the ship is in the entrance, but Figure 9 indicates that the vertical sides of the approach and lock walls generate spurious waves which are dominating the free surface elevations generated by the ship. The free surface potential has the same features: as the ship is in the entrance it seems reasonable, but the spurious waves generated by the presence of the walls obscure the solution when the ship is alongside the approach wall. These spurious waves come from $C^{0}$ smoothness of the free surface potential at the lock walls. The advective terms in the equations are approximated with the HJWENO method (which is a standard eulerian advection algorithm [9]), hence the oscillations do not come from these terms, but the Laplace equation requires $C^{2}$ smoothness of the boundary conditions and this requirement is violated at the sides of the lock. A mollification or regularization of the free surface boundary condition is required to remove the spurious waves in the solution, but this has not been done in these calculations. These results are clearly unsatisfactory for the given model problem. Either the pressure distribution method for representation of walls and structures has to be improved or an alternative method should be sought.

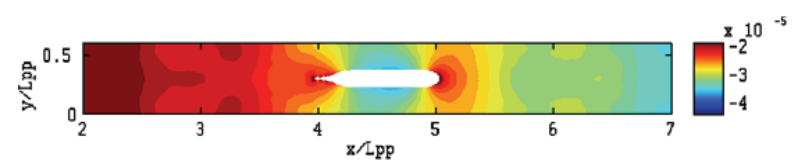

Figure 7: Simulated free surface elevation (in $\mathrm{m}$ ) for ship at position $\mathrm{x} / \mathrm{Lpp}=4.5$ for benchmark test $\mathrm{B}$.

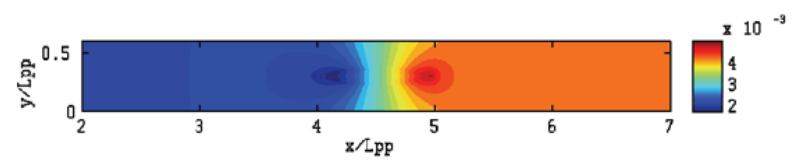

Figure 8: Simulated free surface potential (in $\mathrm{m}^{2} / \mathrm{s}$ ) for ship at position $\mathrm{x} / \mathrm{Lpp}=4.5$ for benchmark test $\mathrm{B}$. 


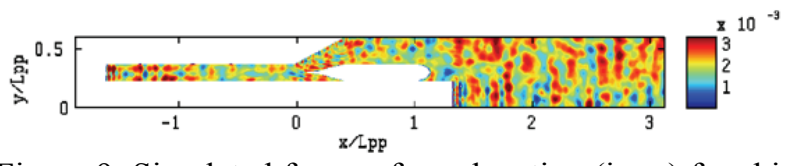

Figure 9: Simulated free surface elevation (in $\mathrm{m}$ ) for ship at position $\mathrm{x} / \mathrm{Lpp}=0.6$ for benchmark test $\mathrm{B}$.

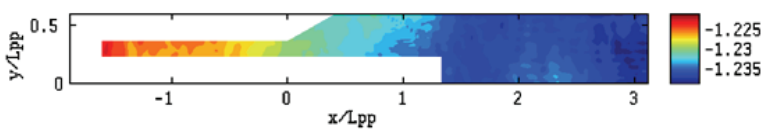

Figure 10. Simulated free surface potential $\left(\right.$ in $\left.\mathrm{m}^{2} / \mathrm{s}\right)$ for ship at position $\mathrm{x} / \mathrm{Lpp}=0.6$ for benchmark test $\mathrm{B}$.

These calculations reveal that the pressure distribution model which considers the ship being flat is too simple. It is necessary to investigate more accurate approximations of the body boundary condition, which does not compromise the overall computational efficiency.

A new weighted least squares (WLS) approximation body boundary condition (BC) has been developed after the Third Conference on Manoeuvring in Shallow and Confined Water. The WLS approximation of the body $\mathrm{BC}$ is similar to immersed boundary methods (IBM) for elliptic equations [10], in particular the inhomogeneous Neumann IBM. The WLS body BC makes it possible to approximate complex geometries like a ship hull inside a structured finite difference grid and utilize the multigrid pre-conditioner for efficient solution of the Laplace equation for the velocity potential.

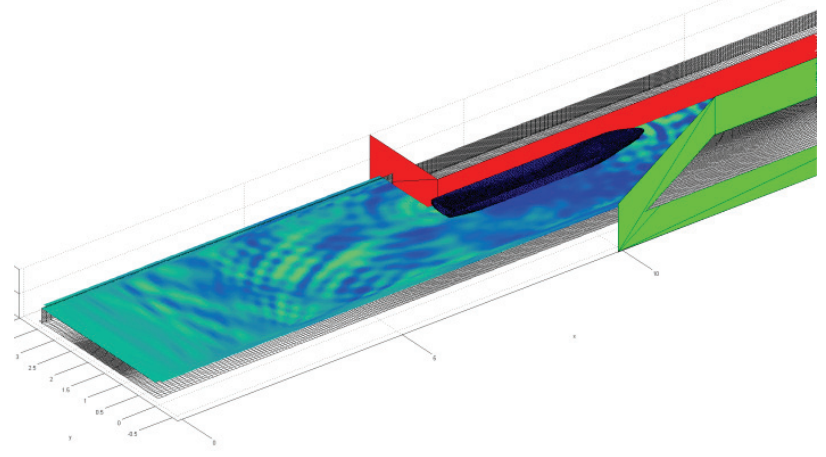

Figure 11: Water elevation at the lock entrance as calculated using the new body $\mathrm{BC}$ for benchmark test B.

Preliminary results from this method are presented in Figure 11 which shows the water elevation at the lock entrance for benchmark test A. The calculation was carried out with a physical domain size of $20.0 \times 3.365 \times$ $0.3 \mathrm{~m}^{3}$ and with a $513 \times 129 \times 17$ finite difference grid. The ship is centred in the grid and it is moving with the ship. Runge Kutta 4 is used for time integration of the linear free surface boundary conditions and the time step is $0.05 \mathrm{~s}$.

\section{USE OF BENCHMARK TEST F TO STUDY THE EFFECT OF DENSITY CURRENTS BY DE LOOR ET AL}

In cases when a sea lock forms a connection to a fresh water shipping canal, the density currents in the approach harbour are an important aspect to consider in the design. Especially when space is limited and the geometry of the approach harbour is asymmetrical, forces caused by these density currents can be significant. de Loor et al. [11] used OpenFOAM to model the forces due to a density current on a ship in front of a lock with an asymmetrical approach harbour and compared their calculations with the results of benchmark test $F$.

Test $\mathrm{F}$ is a static test with density exchange. Tugs and propeller are inactive. The longitudinal forces required to keep the longitudinal position fixed, the time history of the discharge of fresh water and of the opening of the lock gate and the flow pattern at the surface at selected time steps are given in the benchmark data [1]. Benchmark test $\mathrm{F}$ is a complex case because it consists of two phases; the first phase consists of a fresh water levelling current entering the approach harbour, in the second phase the lock gate opens, causing a secondary density current in the approach harbour.

The solver twoLiquidMixingFoam within the OpenFOAM C++ library was used to solve the NavierStokes equations for a mixture consisting of two incompressible fluids with different properties. Per computational cell an average density and average kinematic viscosity is calculated and pressuremomentum coupling is achieved. In these calculations, a rigid lid approximation of the free surface is assumed to reduce numerical complexity and computation time.

The geometry of the lock was created using the open source meshing tool Gmsh. The mesh was created using the snappyHexMesh meshing tool included in the OpenFOAM distribution with a finer region around the ship to increase resolution around the hull. The computational domain spans the lock chamber, approach harbour with closed wall and ship. The computational domain ends about one ship's length behind the stern of the ship, where an outflow boundary condition is applied. The culverts are schematised as one large culvert per side of the lock head instead of two separate culverts per side. Furthermore, in the model setup the culvert outlets seem to be at an angle. The direction of the inflow specified by the boundary condition on the culverts is perpendicular upon the walls of the lock head.

While there is a levelling current flowing, the lock chamber is not part of the computational domain. The door opens after the levelling is complete. The opening sequence of the lock gate is schematised as an instantaneous opening (comparable to the well-known lock-exchange problem). This is a reasonable approximation as the velocity of the occurring density 
current is much smaller than that of the lock gate. So opening of the lock gate is simulated by mapping the results of the levelling current onto a mesh that includes the lock chamber. This second mesh is generated using the same settings for snappyHexMesh. The mesh without lock chamber has approximately 2.4 million cells. The mesh including the lock chamber has approximately 2.6 million cells. The biggest cells are about $1 \times 1 \times 1 \mathrm{~m}^{3}$. The cells in the refinement region around the ship are about $0.5 \times 0.5 \times 0.5 \mathrm{~m}^{3}$.

The results of the calculated longitudinal and lateral forces, which are positive when aimed forward and to starboard respectively, are compared with the measured forces in Figure 12. The calculated forces clearly exhibit spikes, which are caused by the inlet condition at the culverts for the levelling current. The spikes are absent from the moment the lock gate is opened and the inlet condition at the culverts is not applied anymore. The spikes are probably due to pressure changes at the inlet caused by the discretisation of the inflow boundary condition. This causes pressure waves that quickly travel through the domain because of the rigid lid. In reality, the inlet would cause translatory waves as there is a free surface. The longitudinal force is slightly affected by the inlet condition and it has a sort of step-like behaviour which is difficult to see in the figure. The steps coincide with the time steps defined in the inlet condition. Overall the spikes and the step-like behaviour of the longitudinal force do not seem to influence the results greatly. The general comparison between the calculated and measured lateral forces is reasonable. Both peaks in the lateral force are captured, although their magnitudes are slightly overestimated. The magnitude of the lateral force between the two peaks, however, is slightly underestimated and the calculated peaks show a small phase shift.

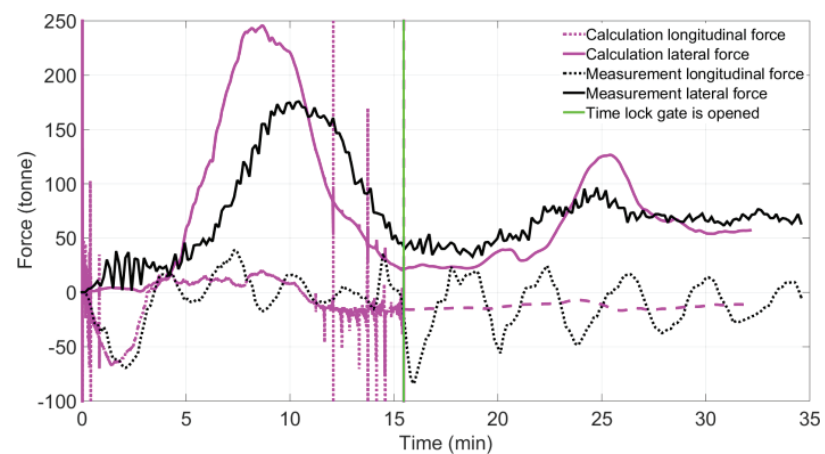

Figure 12: Comparison of the measured and calculated forces for benchmark test F. The green line shows the moment when the door opens.

The measured longitudinal forces show a first peak and then an oscillating behaviour. The first peak corresponds with the initial increase in flow rate from the culverts. The longitudinal force then reduces and starts to oscillate. Although this first peak is calculated quite well, the oscillating behaviour is non-existent in the calculation. However, the calculation seems to give an average of the oscillating force. It is not certain what causes the oscillation, a possible explanation could be a translatory wave generated by the flow from the culverts and reflections of this wave. The translatory waves are not taken into account due to the absence of a free surface. Furthermore, in the model test the ship model was free to heave, pitch and roll, which is not the case in the calculation where the ship has a fixed position, which might influence the measured forces [11].

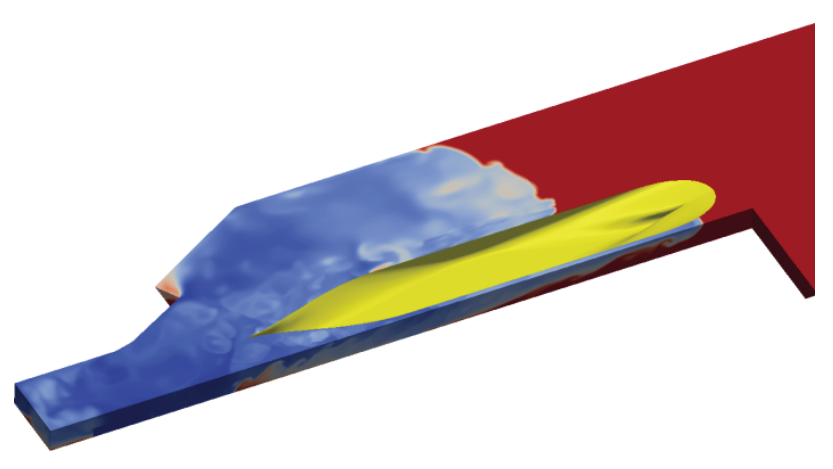

(a)

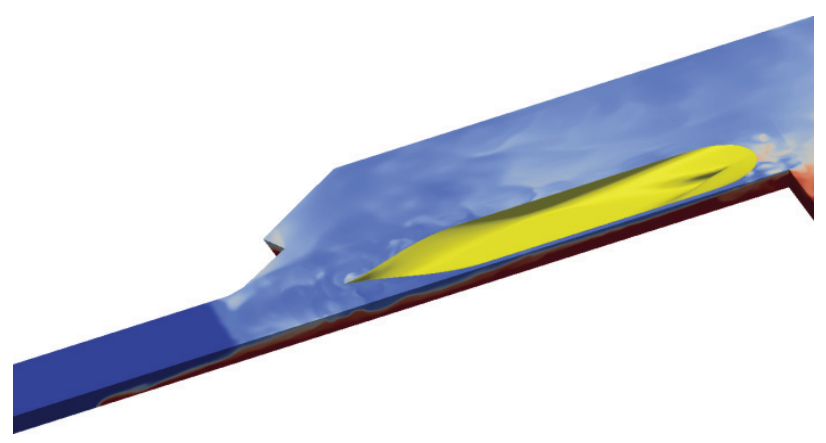

(b)

Figure 13: Density distribution for Benchmark test F (a) $450 \mathrm{~s}$ after the start of the levelling current. Blue is fresh and red is salt water. The density current between the closed wall and the ship can be noticed; (b) approximately $100 \mathrm{~s}$ after opening the lock gate.

Density distributions during the levelling current and after opening the lock gate are shown in Figure 13 a and Figure $13 \mathrm{~b}$ respectively. From the benchmark data no information on the salt concentration was available. However, the method used was validated for lock exchange flows [11]. Figure 13 a shows that the density current between the ship and the closed wall increases in velocity and travels much faster than the density current on the other side of the ship. In contrast, Vrijburcht [12] concluded that the velocity of the density current should decrease in this narrow opening, which is supported by the model test results. Surprisingly enough, even though the behaviour of the density current is not completely modelled correctly, the calculated forces still approximate the measurements reasonably well. The cause for this unexpected behaviour is possibly the rigid lid boundary condition. As there is no possibility for a water level rise near the bow of the ship, the flow causes a pressure increase, which pushes the density current through the narrow opening. In the case of a free surface, the water 
level is free to rise near the bow, which may prevent the large increase in velocity of the density current [11].

de Loor et al. [11] concluded that although the application of CFD is not yet able to predict absolute design values with sufficient accuracy, it is able to provide more insight in the processes at play. It can be a very valuable tool to compare different layouts, designs and scenarios to complement physical model testing.

\section{CAPTIVE MODEL TESTS}

\subsection{EXPERIMENTAL DATA}

Systematic captive model tests were carried out in a feasibility study for receiving bulk carriers with large beam in the Pierre Vandamme Lock in Zeebrugge. This lock has a length of $500 \mathrm{~m}$, a width of $57 \mathrm{~m}$ and a depth of $18.5 \mathrm{~m}$. A scale model $(1 / 75)$ of the lock configuration was constructed with special attention to the asymmetric layout of the approach channel, as shown in Figure 14. The experiments were carried out in the towing tank for manoeuvres in shallow water (co-operation Flanders Hydraulics Research Ghent University), a full description of which is given by Van Kerkhove et al. [13]. The ship model was a 1/75 scale model of a bulk carrier, with main dimensions listed in Table 3 and body plan shown in Figure 15.

The tests started with the model's midship section at zero xposition. After an acceleration phase over a distance of $2 \mathrm{~m}$, the model was towed with constant velocity until the model's midship section reached a position $\mathrm{x}=27.5 \mathrm{~m}$ and was then decelerated over a distance of $0.5 \mathrm{~m}$. Table 4 gives the under keel clearance, eccentricity, drift and speed of the three benchmark tests, which were carried out with the propeller of the ship turned off.

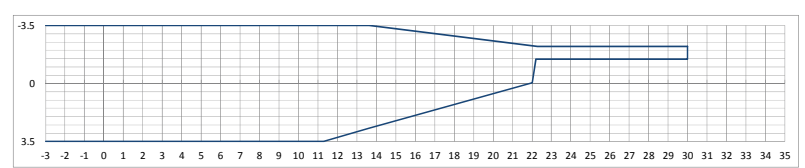

Figure 14: Lock configuration in towing tank for captive model tests (benchmark tests $\mathrm{G}, \mathrm{H}$ and I). The tank walls are determined by $\mathrm{y}= \pm 3.50 \mathrm{~m}$, the lock centreline by $\mathrm{y}=-1.846 \mathrm{~m}$.

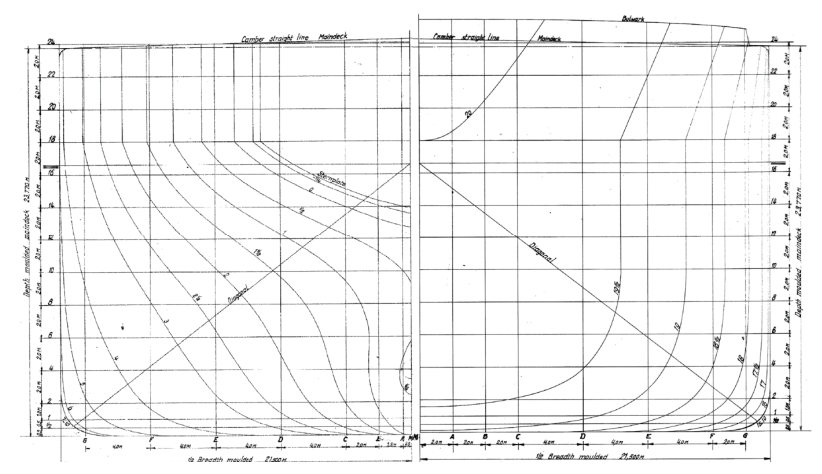

Figure 15: 1/75 scale model of bulk carrier used during captive benchmark tests: body plan
Table 3: Ship characteristics: bulk carrier

\begin{tabular}{|l|l|l|l|}
\hline Particulars & & Full scale & $\begin{array}{l}\text { Scale } \\
\text { model } \\
1 / 75\end{array}$ \\
\hline SHIP & L $_{\text {OA }}(\mathrm{m})$ & 265.0 & 3.533 \\
& L $_{\mathrm{PP}}(\mathrm{m})$ & 259.2 & 3.456 \\
& $\mathrm{~B}(\mathrm{~m})$ & 43.0 & 0.573 \\
& T (m) & 17.342 & 0.231 \\
& $\mathrm{C}_{\mathrm{B}}(-)$ & 0.854 & 0.854 \\
\hline PROPELLER & \#blades & 4 & 4 \\
& D $(\mathrm{m})$ & 6.95 & 0.093 \\
& P/D (-) & 0.663 & 0.663 \\
& AEP (-) & 0.630 & 0.630 \\
\hline RUDDER & Area (m $\left.{ }^{2}\right)$ & 65.7 & 0.0117 \\
\hline
\end{tabular}

Table 4: Overview of benchmark tests with captive models (model scale)

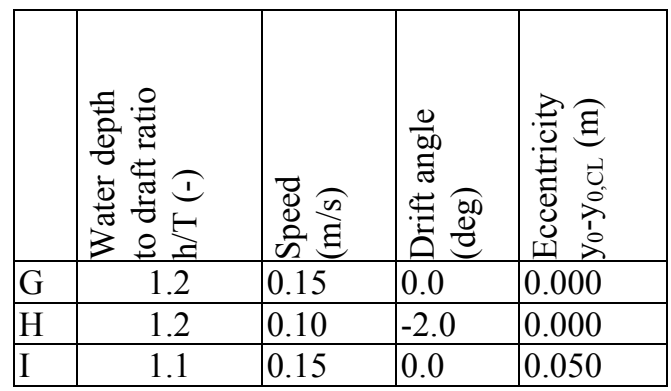

\subsection{NUMERICAL VALIDATION OF BENCHMARK TESTS G AND I BY WANG AND ZOU}

Wang and Zou [14] applied the CFD software package FLUENT to numerically predict the hydrodynamic forces and moments acting on an unappended ship passing through a lock. The ship speed is assumed to be so low that the wave-making effect (and ship squat) can be ignored and that the flow can be assumed to be a viscous flow of incompressible fluid which is governed by the time-averaged continuity equation and the NavierStokes equations. The unsteady RANS equations are then solved in conjunction with a RNG k- $\varepsilon$ turbulence model. A User Defined Function is compiled to define the ship motion. Grid regeneration is dealt with by using the dynamic mesh method and sliding interface technique. The model speed is $0.15 \mathrm{~m} / \mathrm{s}$, and the path length is 27.5 $\mathrm{m}$. The time step is set as $0.1 \mathrm{~s}$, and 20 iterations in a time step. There are a total of 36666 iterations and the simulation time is about 20 hours.

Figure 16 and Figure 17 show the time histories of the calculated hydrodynamic forces and corresponding vertical displacements of the fore and aft perpendiculars in comparison with the model test results. All results are plotted as a function of the longitudinal position of the model's midship section. In general, the present prediction results of hydrodynamic lateral force and yaw moment are in good agreement with the experimental data, while the longitudinal 
force is underestimated because of the increasing blockage in the navigation lock under the test conditions [14]. The vertical displacements at the aft and fore perpendicular do not agree so well. The reason is that in the numerical simulation the ship is fixed and the sinkage and trim are determined from the calculated sinking force and trim moment, while the retardation effect of the restoring force and moment induced by the sinkage and trim cannot be taken into account. On the other hand, in the model test the retardation effect of the restoring force and moment induced by the sinkage and trim actually have an effect in hindering the sinkage and trim, which makes the sinkage and trim smaller than those obtained by numerical simulation.

Having validated the numerical method with the experimental data of benchmark tests $\mathrm{G}$ and $\mathrm{I}$, numerical simulations were carried out to investigate a number of different configurations or to study selected parameters. Figure 18 shows the differences in hydrodynamic behaviour when the ship model enters or leaves the lock. The numerical simulation starts with the ship's midship section located at $\mathrm{x}=0 \mathrm{~m}$ for entering the lock and at $\mathrm{x}=28 \mathrm{~m}$ for leaving the lock. The ship model moves along the centre line of the lock chamber at a constant speed of $0.15 \mathrm{~m} / \mathrm{s}$.

Wang and Zou then carried out numerical calculations for varying eccentricities and water depths [14]. It was found that the eccentricity only has an effect on the hydrodynamic quantities when the bow of ship model reaches the lock entrance. The water depth has a much more significant effect on the hydrodynamic quantities than the eccentricity. As the water depth decreases, the magnitude of hydrodynamic forces and the vertical displacements of fore and aft perpendiculars increase.

The effects of the approach wall configuration, lock configuration symmetry and lock chamber breadth were also studied numerically [15]. A left closed wall increases the hydrodynamic forces, while a right closed wall reduces the hydrodynamic forces. The lock configuration symmetry can reduce lateral force, rolling moment and yawing moment to a larger extent. The lock chamber breadth has a major effect on the hydrodynamic quantities. Hence, a good configuration can reduce the hydrodynamic forces and make a ship pass through the lock safely. Therefore, it is important to design an appropriate lock configuration.

The effects of a ship passing through the Pierre Vandamme Lock were also studied when a ship is berthed near the lock entrance [16]. Quantitative predictions of the longitudinal force, the lateral force and the yaw moment were obtained at different ship speeds and water depths and for different lateral and longitudinal positions of the berthed ship.

The numerical method proposed by Wang and Zou can qualitatively predict the ship-lock hydrodynamic interaction and it can provide a certain guidance on safe manoeuvring. In addition, numerical studies can be helpful to understand the influence of lock configuration and may provide certain guidance to the lock design [14].

\section{CONCLUSIONS}

At the $3^{\text {rd }}$ International Conference on Ship Manoeuvring in Shallow and Confined Water, which had a nonexclusive focus on Ship Behaviour in Locks, several authors used benchmark data that had been made publicly available to validate numerical tools.

By means of benchmark test data of a self-propelled container carrier entering a lock, Henn [5] found that a fast numerical method leads to a more accurate simulation of lock manoeuvres than the parametric models, that are used in up-to-date ship manoeuvring simulators.

Vergote et al. [6] used the same benchmark test to evaluate the improvements made to a numerical model describing the wave-system in a lock. The model is only one-dimensional and the comparison with the experimental results illustrates the limits in the range of applicability. The comparison thus gives indications that further improvements should be made to the model before it can be implemented in a ship manoeuvring simulator.

Lindberg et al. [8] used benchmark test data to evaluate whether a numerical model for real-time ship-wave calculation and ship-structure and ship-ship interaction in a full mission marine simulator could be applied for the case when a ship is entering a lock. Early calculations revealed that the boundary conditions were not considered sufficiently well. Recent calculations using a weighted least squares (WLS) approximation for the body boundary condition (BC) show promising results without compromising computational effort.

de Loor et al. [11] used the benchmark test data of a static test with density exchange to study the capabilities of a CFD package. The analysis demonstrated that even though CFD is not yet able to predict absolute design values with sufficient accuracy, it provides insight in the physical processes at play.

Wang and Zou [14] applied CFD to numerically predict the hydrodynamic forces and moments acting on an unappended ship passing through a lock. The comparison revealed that CFD is able to qualitatively predict the ship-lock hydrodynamic interaction and it can provide a certain guidance on safe manoeuvring.

At present, there is a lot of research going on in the development of numerical tools to study hydrodynamic problems. For the validation of the calculations, these tools require experimental data, which are often not publicly available. This paper has attempted to show that open-access benchmark data can significantly contribute to the development and further improvement of numerical models. The comparison of experiments and numerical models has also shown that it is strongly 
recommended to measure the flow characteristics during lock entry (or exit) experiments.

It remains a challenge to develop numerical models for lock entries that are fast and accurate enough to be implemented in a ship manoeuvring simulator. When a ship enters a lock, the viscous effects in this very confined environment become important and can no longer be ignored. Suitable viscous terms therefore need to be introduced in the numerical model when the ship is in or near the lock in order to avoid inaccuracy. Scaling issues when extrapolating from model to full scale will also have to be addressed.

At present, CFD requires significant computation time and is therefore not suitable to be implemented in a ship manoeuvring simulator. However, CFD can be a very valuable tool to compare different layouts, designs and scenarios to complement physical model testing.

\section{ACKNOWLEDGEMENTS}

The authors wish to thank the Panama Canal Authorities, who commissioned the tests described in Section 2.1.

\section{REFERENCES}

1. VANTORRE, M., DELEFORTRIE, G., MOSTAERT, F., Behaviour of ships approaching and leaving locks: Open model test data for validation purposes, 3rd International Conference on Ship Manoeuvring in Shallow and Confined Water: with non-exclusive focus on Ship Behaviour in Locks, R.I.N.A., pp 337-352, 2013.

2. VANTORRE, M., RICHTER, J., Maneuverability in lock access channels, "What's new in the design of navigation locks" 2nd International Workshop, PIANC - New Orleans, 13-14 Sept.2011, Paper 6-2, 2011.

3. DELEFORTRIE, G., WILLEMS, M., VANTORRE, M., LAFORCE, E., Behavior of post panamax vessels in the Third Set of Panama locks, MARSIM '09 Conference, Proceedings, Panama Canal Authority; International Marine Simulator Forum, p. S1:1-9, 2009.

4. DELEFORTRIE, G., WILLEMS, M., LAFORCE, E., VANTORRE, M., DE MULDER, T., DE REGGE, J., WONG, J., Tank test of vessel entry and exit for third set of Panama locks, The Proceedings of the International Navigation Seminar following PIANC AGA 2008, China Communications Press, pp 517-530, 2008.

5. HENN, R., Real-time simulation of ships manoeuvring in locks, 3rd International Conference on Ship Manoeuvring in Shallow and Confined Water: with non-exclusive focus on Ship Behaviour in Locks, R.I.N.A., pp 215-219, 2013.

6. VERGOTE, T., ELOOT, K., VANTORRE, M., VERWILLIGEN, J., Hydrodynamics of a ship while entering a lock, 3rd International Conference on Ship Manoeuvring in Shallow and Confined Water: with non-exclusive focus on Ship Behaviour in Locks, R.I.N.A., pp 281289, 2013.

7. VRIJBURCHT, A., Calculations of wave height and ship speed when entering a lock, Delft Hydraulics Publication no. 391, 1988.

8. LINDBERG, O., GLIMBERG, S.L., BINGHAM, H.B., ENGSIG-KARUPF, A.P., SCHJELDAHL, P. J., Real-time simulation of ship-structure and ship-ship interaction, 3rd International Conference on Ship Manoeuvring in Shallow and Confined Water: with non-exclusive focus on Ship Behaviour in Locks, R.I.N.A., pp 257-264, 2013.

9. SERNA, S., QIAN, J., Fifth-Order Weighted Power-ENO Schemes for Hamilton-Jacobi Equations, Journal of Scientific Computing, Volume 29(1), pp 57-81, 2005.

10. LIU, X.-D., FEDKIW, R.P., KANG, M., A Boundary Condition Capturing Method for Poisson's Equation on Irregular Domains, Journal of Computational Physics, Volume 160(1), pp 151-178, 2000.

11. DE LOOR, A., VAN DER HOUT, J., WEILER, O.M., KORTLEVER, W. C. D., The use and validation of OpenFOAM to determine the lateral and longitudinal forces exerted on a vessel in the lock and in the lock approach, 3rd International Conference on Ship Manoeuvring in Shallow and Confined Water: with nonexclusive focus on Ship Behaviour in Locks, R.I.N.A, 2013, pp 157-166, 2013.

12. VRIJBURCHT, A., Forces on Ships in a Navigation Lock Induced by Stratified Flows, Delft Hydraulics Publication no. 448, 1991.

13. VAN KERKHOVE, G., VANTORRE, M., DELEFORTRIE, G., Advanced model testing techniques for ship behaviour in shallow and confined water, $A M T$ '09 - The 1st International Conference on Advanced Model Measurement Technology for the EU Maritime Industry, 1st 2nd September 2009, Ecole Centrale de Nantes, France. pp 158-172, 2009.

14. WANG, H.-Z., ZOU, Z.-J., Numerical study on hydrodynamic behaviour of ships sailing in locks, 3rd International Conference on Ship Manoeuvring in Shallow and Confined Water: with non-exclusive focus on Ship Behaviour in Locks, R.I.N.A, pp 129-134, 2013.

15. WANG, H.-Z., ZOU, Z.-J., Numerical Prediction of Hydrodynamic Forces on a Ship Passing through a Lock with Different Lock Shape, Journal of Hydrodynamics, Volume 26(1), pp 1-9, 2014.

16. WANG, H.-Z., ZOU, Z.-J., Numerical study on hydrodynamic interaction between a berthed ship and a ship passing through a lock, Ocean Engineering, Volume 88, pp 409-425, 2014. 


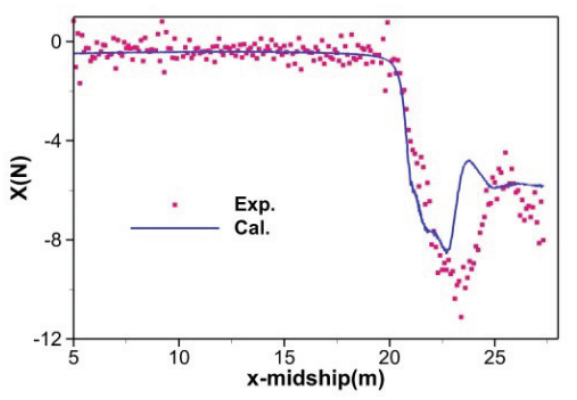

(a) Comparison of longitudinal force

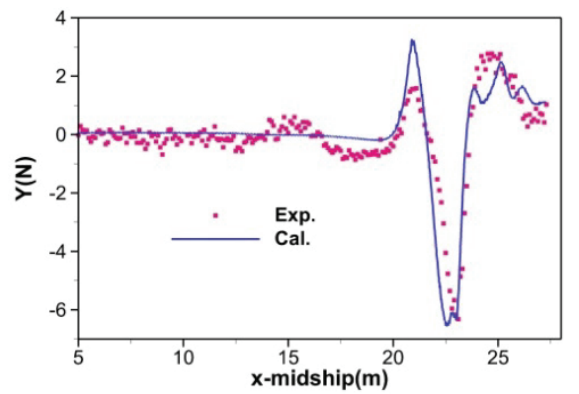

(b) Comparison of lateral force

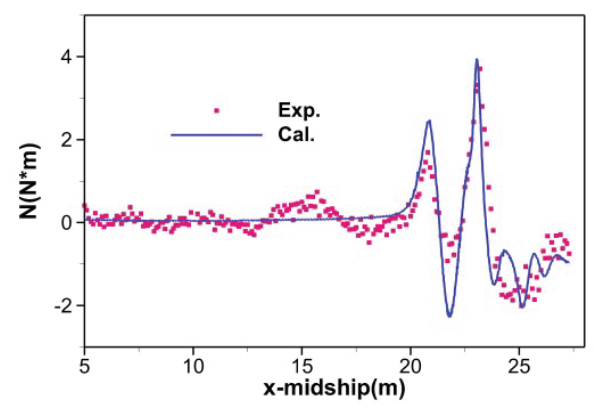

(c) Comparison of yaw moment

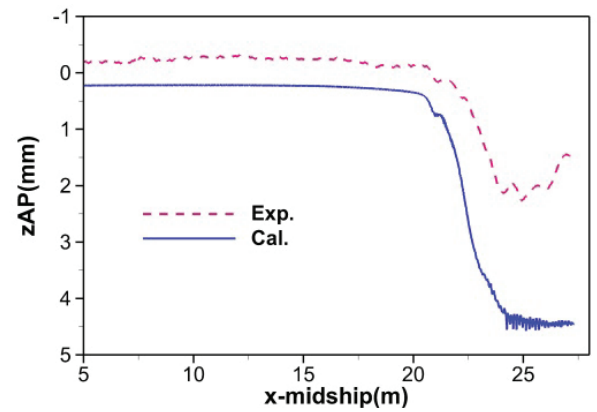

(d) Comparison of vertical displacement of the aft perpendicular

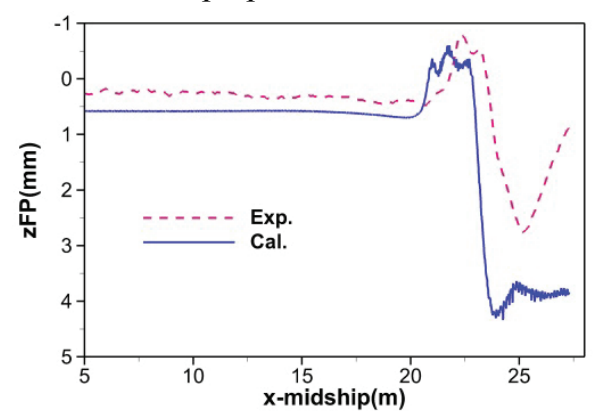

(e) Comparison of vertical displacement of the fore perpendicular

Figure 16: Comparison of calculated and experimental results of benchmark test $\mathrm{G}$.

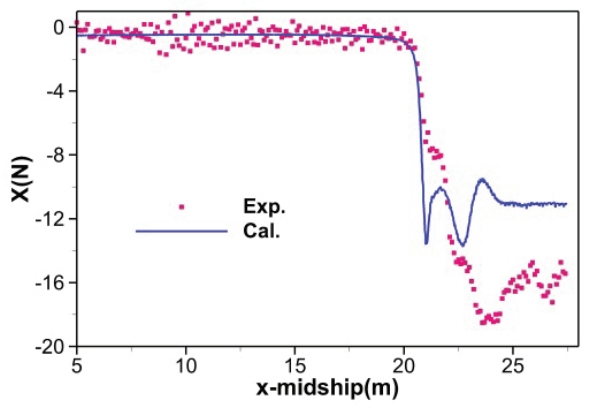

(a) Comparison of longitudinal force

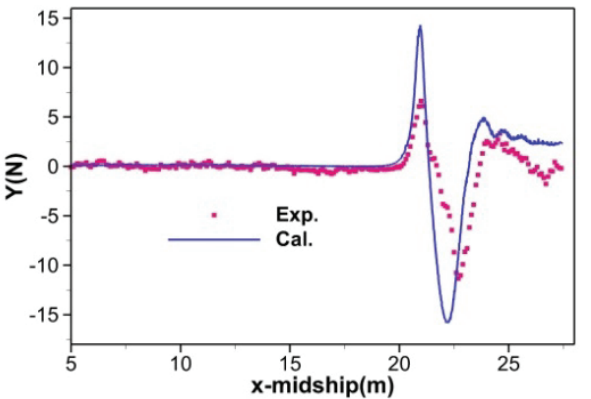

(b) Comparison of lateral force

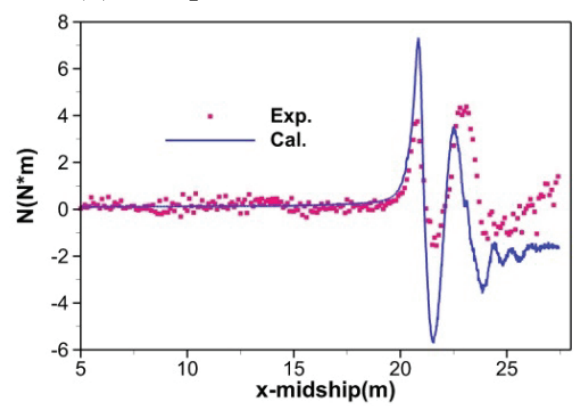

(c) Comparison of yaw moment

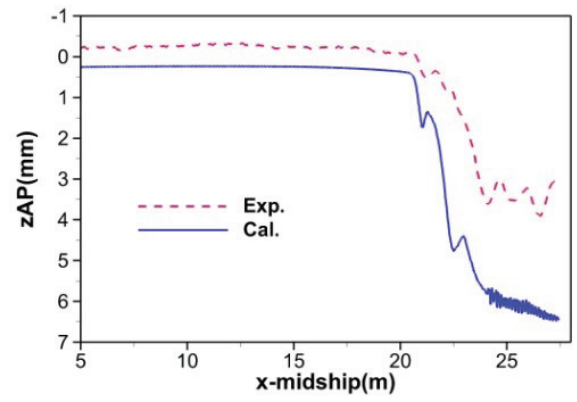

(d) Comparison of vertical displacement of the aft perpendicular

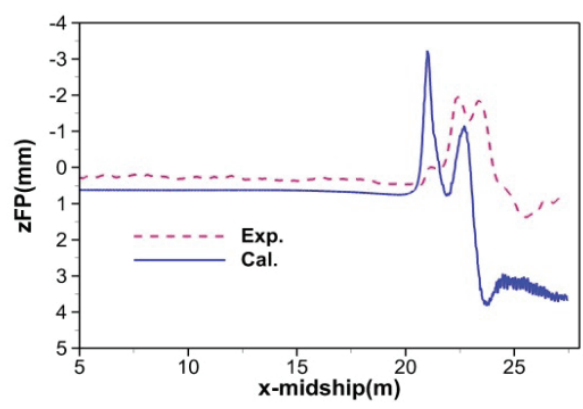

(e) Comparison of vertical displacement of the fore perpendicular

Figure 17: Comparison of calculated and experimental results of benchmark test I. 


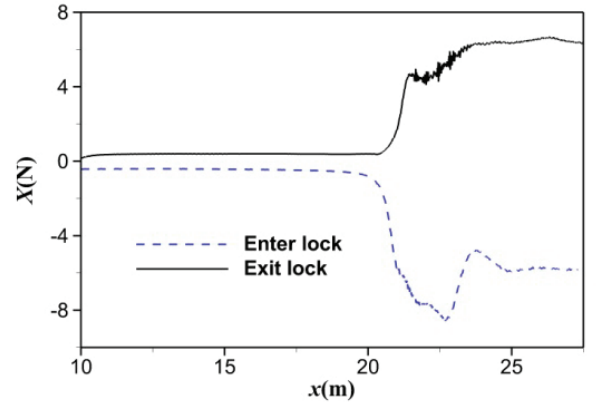

(a) Comparison of longitudinal force

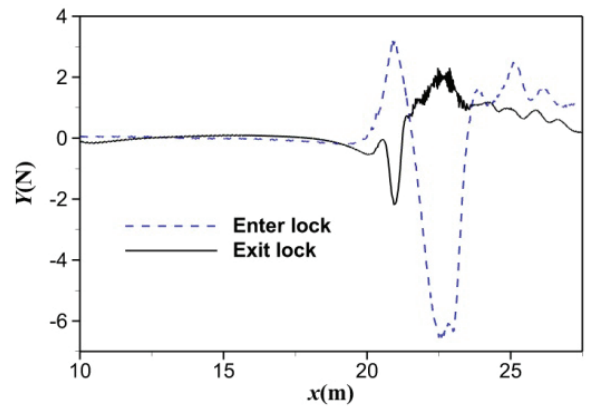

(b) Comparison of lateral force

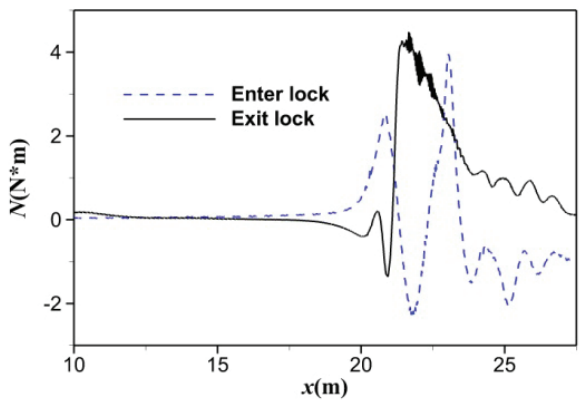

(c) Comparison of yaw moment

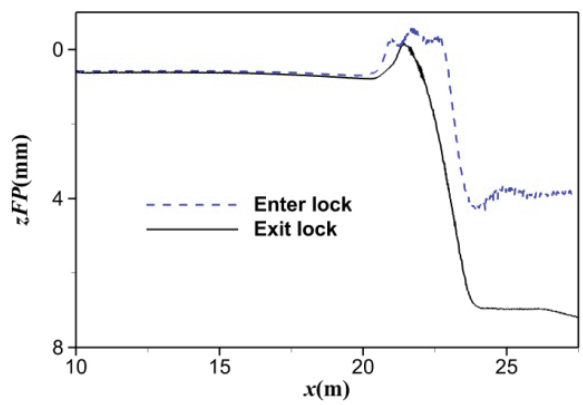

(d) Comparison of vertical displacement of the aft perpendicular

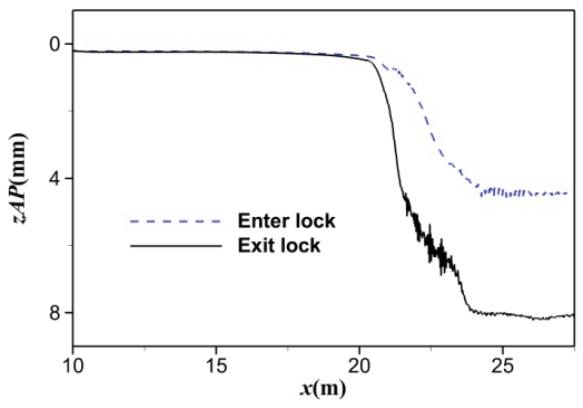

(e) Comparison of vertical displacement of the fore perpendicular

Figure 18: Comparison of predicted hydrodynamic behaviour when the ship model enters the lock (moving from left to right) or leaves the lock (moving from right to left) using CFD. 